\title{
Size Effect of Hard Magnetic Properties of Fe-Nb-B-Tb Milled Alloys
}

\author{
K. Granek*, G. ZióŁkowski, A. Chrobak, J. Klimontko and E. Talik \\ Institute of Physics, University of Silesia, Uniwersytecka 4, 40-007 Katowice, Poland
}

\begin{abstract}
The paper refers to magnetic and structural properties of powders made of Fe-Nb-B-Tb ultra-high coercive alloy. The initial alloy was milled in a low energy mill for $1 \mathrm{~h}$ and $14 \mathrm{~h}$. With increasing milling time we observed gradual deterioration of hard magnetic properties i.e. the coercive field decreases from $5.51 \mathrm{~T}$ to $0.14 \mathrm{~T}$ for the bulk alloy and $14 \mathrm{~h}$ milled powder, respectively. However, for the $1 \mathrm{~h}$ milling time the micrometric powder reveals quite high coercivity of $2.77 \mathrm{~T}$ which is promising for possible applications in magnetic composites.
\end{abstract}

DOI: 10.12693/APhysPolA.133.645

PACS/topics: 81.07.Bc, 75.50.Tt, 75.60.d, 76.80. + y

\section{Introduction}

Magnetic materials are very important in modern technologies [1-5]. New and continuously increasing requirements can be fulfilled by modern nanostructured magnetic composites containing different phases characterized by different magnetic properties. In the field of hard magnetics, interactions between the phases are especially important and can lead to an appearing of new and unique properties. Recently we have reported ultrahigh coercivity of Fe-Nb-B-RE bulk nanocrystalline alloys produced by the vacuum suction casting technique, i.e. more than $7 \mathrm{~T}$ at room temperature and after some field annealing [6-8]. It should be underlined that in the field of bulk materials this is a unique feature, giving new opportunities to designing new magnetic materials. It was shown that the examined alloys contain some ultrahard magnetic objects that do not directly contribute to the magnetization precesses but, via direct interactions, can influence magnetic characteristics of the whole ?????? $\left(\mathrm{Fe}_{80} \mathrm{Nb}_{6} \mathrm{~B}_{14}\right)_{0.88} \mathrm{~Tb}_{0.12}$ powders made of bulk alloy. Important is the question if such powders can be considered as a source of high magnetic anisotropy in new alloy. These types of materials have a potential to be a base for a new type of spring-exchange composites with magnetic characteristics better than conventional Nd-based permanent magnets.

The aim of this work is to study the size effect of hard magnetic properties of $\left(\mathrm{Fe}_{80} \mathrm{Nb}_{6} \mathrm{~B}_{14}\right)_{0.88} \mathrm{~Tb}_{0.12}$ composites containing ultra-high coercive phases.

\section{Experimental procedure}

The powders were obtained from the $\left(\mathrm{Fe}_{80} \mathrm{Nb}_{6} \mathrm{~B}_{14}\right)_{0.88} \mathrm{~Tb}_{12}$ bulk alloy. In the first step, the bulk samples were prepared by the mold casting technique using self-designed vacuum suction apparatus. In the second step, the samples were milled in the

*corresponding author; e-mail: krzysztof.granek@gmail.com low energy ball mill. In order to obtain powders with different pulverization degrees, the milling time was equal to $1 \mathrm{~h}$, and $14 \mathrm{~h}$. The whole milling procedure was performed in a glovebox in an argon atmosphere. The X-ray diffraction experiments (XRD) were carried out using a high-resolution PANalytical Empyrean diffractometer with $\mathrm{Cu} \mathrm{K} \mathrm{K}_{\alpha}$ radiation $(40 \mathrm{kV}, 30 \mathrm{~mA})$ equipped with a PIXcel detector. The phase analysis was performed by the "X'Pert High Score Plus" searchmatch computer program. Magnetic measurements were carried out by using a PPMS device (Quantum Design $\mathrm{P} 547$ ), in the room temperature and magnetic field up to $7 \mathrm{~T}$. Microstructural characterization of powders was performed using scanning electron microscopy (SEM).

\section{Results and discussion}

Figure 1 presents the XRD patterns for the powders milled $1 \mathrm{~h}, 14 \mathrm{~h}$ and, as a reference, XRD pattern for the basic alloy. As shown, the increasing milling time causes the observed broadening of the XRD peaks that is surely related to a decreasing of crystallites sizes. In all cases, the detected reflexes fit to the $\mathrm{Tb}_{2} \mathrm{Fe}_{14} \mathrm{~B}$ phase, which is the main component of the studied samples. For the bulk alloy and after $1 \mathrm{~h}$ milling a small amount of $\mathrm{Fe}_{2} \mathrm{~Tb}$ was detected, while after $14 \mathrm{~h}$ milling a $20 \%$ presence of $\mathrm{Fe}$, $\mathrm{Fe}_{2} \mathrm{~B}$ and $\mathrm{Tb}$ was also observed. For the first two cases dominant is the hard magnetic phase of $\mathrm{Tb}_{2} \mathrm{Fe}_{14} \mathrm{~B}$. The increase of the milling time to $14 \mathrm{~h}$ leads to significant contribution of magnetically soft phases $\left(\mathrm{Fe}\right.$ and $\left.\mathrm{Fe}_{2} \mathrm{~B}\right)$. Detailed information about the phase composition, mean crystallites diameters and crystallites strain, determined by the use of the Scherrer (Sch) and Williamson-Hall (W$\mathrm{H})$ methods, are collected in Table I.

Figure 2. shows magnetic hysteresis loops for powders milled by $1 \mathrm{~h}, 14 \mathrm{~h}$ and, as a reference, for the bulk alloy. It can be seen that increasing of the milling time leads to a deterioration of hard magnetic properties of the studied powders. In fact, coercive field gradually decreases with increasing milling time.

Simultaneously, an increase of magnetization in $7 \mathrm{~T}$ is observed (see Table II). One may notice that the mag- 


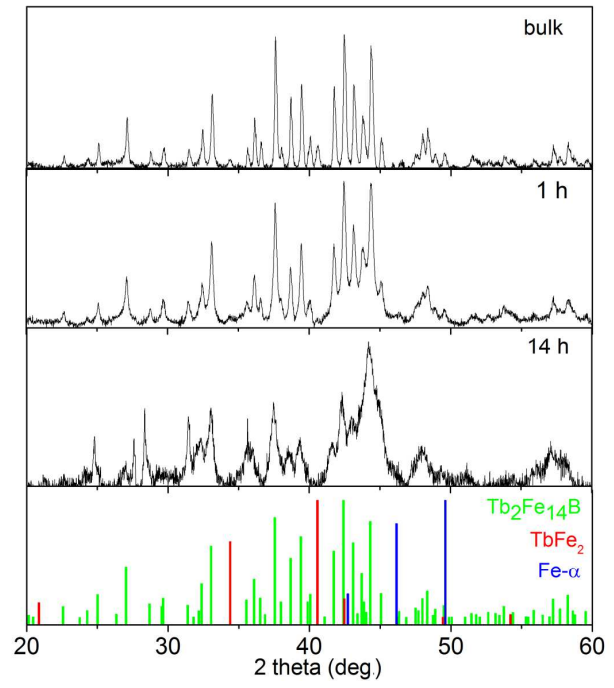

Fig. 1. XRD patterns for bulk alloy and powders milled $1 \mathrm{~h}$ and $14 \mathrm{~h}$.

TABLE I

Phases content, mean crystallites diameters $D$ and strain for the bulk alloy and powders of $\left(\mathrm{Fe}_{80} \mathrm{Nb}_{6} \mathrm{~B}_{14}\right)_{0.88} \mathrm{~Tb}_{12}$.

\begin{tabular}{c|c|c|c}
\hline \hline Sample & $\begin{array}{c}\text { Phases } \\
\text { content } \\
\pm 2 \%\end{array}$ & $\begin{array}{c}D[\mathrm{~nm}] \\
\pm 10 \% \\
\mathrm{Sch} / \mathrm{W}-\mathrm{H}\end{array}$ & $\begin{array}{c}\text { Strain } \\
{\left[10^{-3}\right]} \\
\pm 10 \% \\
(\mathrm{~W}-\mathrm{H})\end{array}$ \\
\hline $\begin{array}{c}\text { bulk } \\
\text { alloy }\end{array}$ & $\begin{array}{c}\mathrm{Tb}_{2} \mathrm{Fe}_{14} \mathrm{~B}: 97 \% \\
\mathrm{Fe}_{2} \mathrm{~Tb}: 3 \%\end{array}$ & $35 /-$ & - \\
$\begin{array}{c}\mathrm{Tb}_{2} \mathrm{Fe}_{14} \mathrm{~B}: 98 \% \\
\mathrm{Fe}_{2} \mathrm{~Tb}: 2 \%\end{array}$ & $30 / 27$ & 0.9 \\
$\begin{array}{c}14 \mathrm{~h} \\
\text { milled }\end{array}$ & $\begin{array}{c}\mathrm{Tb}_{2} \mathrm{Fe}_{14} \mathrm{~B}: 80 \% \\
\mathrm{Fe}, \mathrm{Fe}_{2} \mathrm{~B}, \mathrm{~Tb}: 20 \%\end{array}$ & $12 / 17$ & 2.1
\end{tabular}

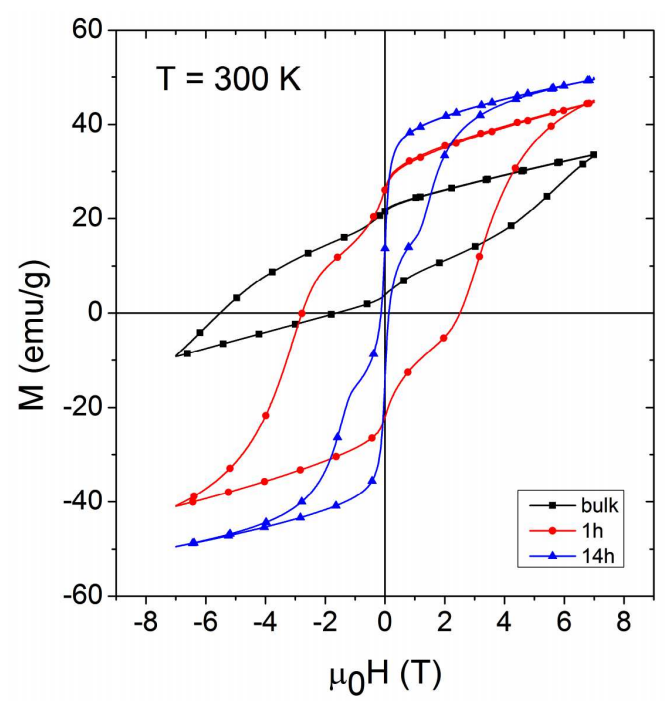

Fig. 2. Magnetic hysteresis loops for bulk alloy and powders milled $1 \mathrm{~h}$ and $14 \mathrm{~h}$ measured in room temperature. netization process occurs in two steps, let say, the hysteresis contain magnetically hard and soft components. The hard component is surely attributed to the dendrite $\mathrm{Tb}_{2} \mathrm{Fe}_{14} \mathrm{~B}$ phase (as for the bulk), while the soft one to $\mathrm{Fe}, \mathrm{Fe}_{2} \mathrm{~Tb}$ and the destroyed $\mathrm{Tb}_{2} \mathrm{Fe}_{14} \mathrm{~B}$ phases. Moreover, the shape of the hysteresis also changes. For the initial bulk alloy the hysteresis curve is strongly asymmetric due to the presence of some ultra-high coercive objects [8]. For the obtained powders the shape is almost symmetric which suggests gradual disappearing of the magnetically hard objects.

TABLE II

Selected magnetic parameters (coercive field $\mu_{0} H_{C}$, magnetic remanence $M_{R}$ and magnetization in $7 \mathrm{~T} M_{7 T}$ ) for the bulk alloy and powders.

\begin{tabular}{c|c|c|c}
\hline \hline Sample & $\mu_{0} H_{C}[\mathrm{~T}]$ & $M_{R}[\mathrm{emu} / \mathrm{g}]$ & $M_{7 T}[\mathrm{emu} / \mathrm{g}]$ \\
\hline bulk alloy & 5.51 & 21.7 & 33.6 \\
1 h milled & 2.77 & 26.1 & 45.1 \\
14 h milled & 0.14 & 13.5 & 49.9
\end{tabular}

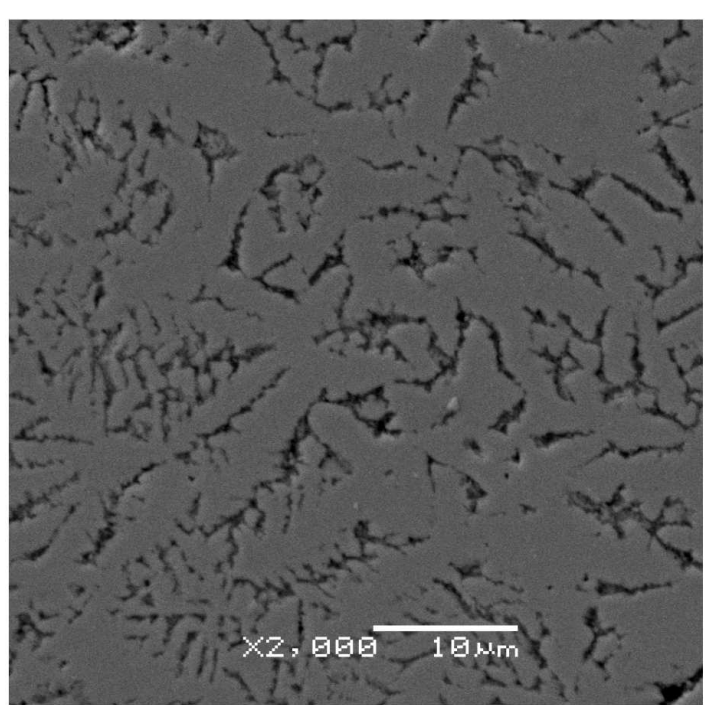

Fig. 3. SEM picture for the bulk alloy.

Figures 3, 4 and 5 show SEM pictures of the bulk material, $1 \mathrm{~h}$ milled and $14 \mathrm{~h}$ milled powders, respectively. In the case of the initial alloy, one may observe dendritelike grains of the hard magnetic $\mathrm{Tb}_{2} \mathrm{Fe}_{14} \mathrm{~B}$ phase. Detailed analysis of the observed microstructure was reported in [8]. For the powder milled for $1 \mathrm{~h}$, the detected grain sizes oscillate about 1 micrometer. This order of magnitude corresponds with dendrite branches size shown in Fig. 3. Based on this, one may suppose that after $1 \mathrm{~h}$ milling the dendrite-like structure of bulk material wasn't totally destroyed, that is reflected in relatively high coercivity value of $2.77 \mathrm{~T}$.

For the powder milled $14 \mathrm{~h}$ the grain size decreases to nanometric values of about $100 \mathrm{~nm}$ which leads to significant decrease of coercivity.

The presented results indicate that hard magnetic properties of the powders made of $\left(\mathrm{Fe}_{60} \mathrm{Nb}_{6} \mathrm{~B}_{14}\right)_{0.88} \mathrm{~Tb}_{12}$ 


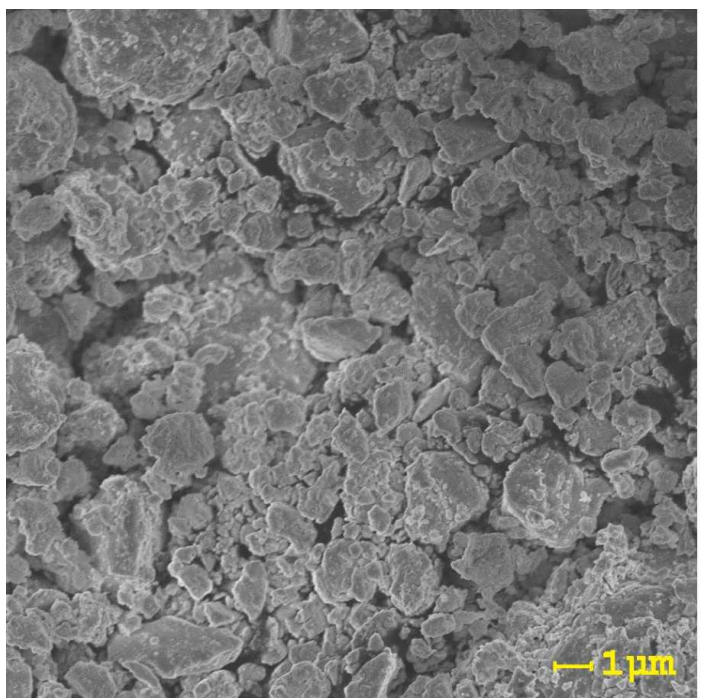

Fig. 4. SEM picture for $1 \mathrm{~h}$ milled powder.

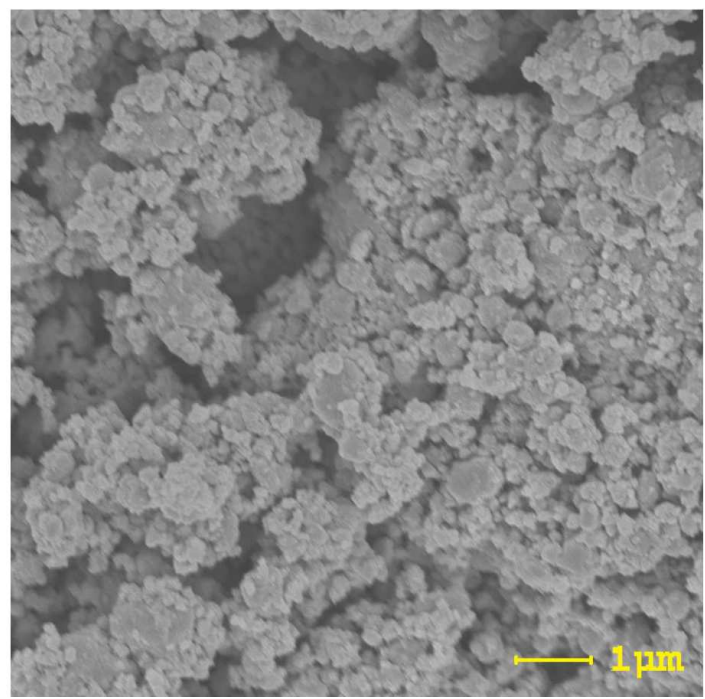

Fig. 5. SEM picture for $14 \mathrm{~h}$ milled powder.

bulk alloy deteriorate with increasing pulverization degree. However, after $1 \mathrm{~h}$ milling time the coercivity is still high (2.77 $\mathrm{T}$ in room temperature) while magnetization in $7 \mathrm{~T}$ and remanence increase. Generally, the observed deterioration is caused by two factors: i) changes in microstructure and ii) appearing of uncoupled magnetically soft phases of $\mathrm{Fe}$ and $\mathrm{Fe}_{2} \mathrm{~Tb}$. The first factor is important for the $1 \mathrm{~h}$ milled powder, where any significant phase changes were not observed. This means that a partial break of the dendrite microstructure is responsible for the decrease of coercivity. Grinding to the nanometric grains causes further destroying of the initial microstructure and remarkable contribution of the Fe and $\mathrm{Fe}_{2} \mathrm{~Tb}$ phases which is clearly shown in Fig. 2. One can state that for the future applications in magnetic composites preferred are micrometric grains saving the phase composition as well as dendrite-like microstructure of the initial alloy.

\section{Conclusions}

In relation to the $\left(\mathrm{Fe}_{80} \mathrm{Nb}_{6} \mathrm{~B}_{14}\right)_{0.88} \mathrm{~Tb}_{12}$ powders, the conclusions can be summarized as follows:

- With increasing milling time, the mean size of the crystallites decreases. The phase composition doesn't change significantly up to $1 \mathrm{~h}$ milling time while for the $14 \mathrm{~h}$ milled powder the $\mathrm{Fe}$ and $\mathrm{Fe}_{2} \mathrm{~Tb}$ phases appear. Simultaneously, after $1 \mathrm{~h}$ and $14 \mathrm{~h}$ milling time the mean grain sizes also decrease from about $1 \mu \mathrm{m}$ to $100 \mathrm{~nm}$, respectively.

- Increase of the milling time leads to the observed deterioration of hard-magnetic properties. Nevertheless, for the milling time equal to $1 \mathrm{~h}$, coercivity is still relatively high, i.e. about $3 \mathrm{~T}$ at room temperature. This is related to the micrometric grains size which partially preserves dendrite-like structure responsible for ultra high coercivity of the bulk alloy.

- Further pulverization of material leads to a destroing of dendrite-like structure and significant decrease of hard magnetic properties.

- Proper control of milling process may lead to creation of powders having good hard-magnetic properties. Therefore, such powders can be considered as a source of high magnetic anisotropy in new composites containing ultra-high coercive phases.

\section{Acknowledgments}

This work was supported by National Science Centre in Poland by the grant 2015/19/B/ST8/02636.

\section{References}

[1] J.M.D. Coey, Scr. Mater. 67, 524 (2012).

[2] N. Poudyal, J. Ping Liu, J. Phys. D: Appl. Phys. 46, 043001 (2013).

[3] J. Zhang, K.Y. Lim, Y.P. Fenga, Y. Li, Scr. Mater. 56, 943 (2007).

[4] J. Liu, H. Sepehri-Amin, T. Ohkubo, K. Hioki, A. Hattori, T. Schrefld, K. Hono, Acta Mater. 82, 336 (2015).

[5] R.M. Liu, M. Yue, R. Na, Y.W. Deng, D.T. Zhang, W.Q. Liu, J.X. Zhang, J. Appl. Phys. 109, 07A760 (2011).

[6] A. Chrobak, G. Ziółkowski, N. Randrianantoandro, J. Alloys Comp. 583, 48 (2014).

[7] A. Chrobak, G. Ziółkowski, N. Randrianantoandro, J. Klimontko, G. Haneczok, J. Alloys Comp. 537, 154 (2012).

[8] A. Chrobak, G. Ziółkowski, N. Randrianantoandro, J. Klimontko, D. Chrobak, K. Prusik, J. Rak, Acta Mater. 98, 318 (2015). 